Check for updates

Cite this: Mater. Adv., 2020, 1, 1829

Received 10th June 2020

Accepted 3rd August 2020

DOI: $10.1039 / \mathrm{d} 0 \mathrm{ma} 00406 \mathrm{e}$

rsc.li/materials-advances

\title{
Electron transport in a sequentially doped naphthalene diimide polymer $\dagger$
}

\author{
Khaled Al Kurdi, ${ }^{a}$ Shawn A. Gregory, ${ }^{b}$ Samik Jhulki, ${ }^{a}$ Maxwell Conte, ${ }^{a}$ \\ Stephen Barlow, ID a Shannon K. Yee ${ }^{c}$ and Seth R. Marder*ab
}

\begin{abstract}
The effects of sequential $\mathrm{n}$-doping on a high-electron-mobility naphthalene-diimide-based copolymer poly[( $N, N^{\prime}$-bis(2-decyltetradecyl)-naphthalene-1,8:4,5-bis(dicarboximide)-2,6-diyl)-(selenophene-2,5-diyl)(benzo[c][1,2,5]thiadiazole-4,7-diyl)-(selenophene-2,5-diyl)], PNBS, are reported. Grazing-incidence XRD measurements show that PNBS doped with 2,2'-bis(4-(dimethylamino)phenyl)-1,1',3,3'-tetramethyl$2,2^{\prime}, 3,3^{\prime}$-tetrahydro- $1 H, 1^{\prime} H-2,2^{\prime}$-bibenzo[d] imidazole, $(\mathrm{N}-\mathrm{DMBI})_{2}$, has increased order relative to both the pristine polymer and a film doped with ruthenium pentamethylcyclopentadienyl mesitylene dimer. Films of PNBS optimally doped with $(\mathrm{N}-\mathrm{DMBI})_{2}$ show electrical conductivities approaching $2 \mathrm{mS} \mathrm{cm}^{-1}$ in air. Temperature-dependent electrical measurements suggest that the polaronic charge carriers are highly localized, which is consistent with the moderate conductivity values obtained.
\end{abstract}

\section{Introduction}

Electrical doping of organic semiconductors with redox-active molecules is increasingly used to increase conductivity and modify charge-injection/-extraction barriers. ${ }^{1,2}$ Doped films of small-molecule semiconductors are often fabricated by co-evaporation of semiconductor and dopant molecules. For solution-processible molecular and polymeric semiconductors, the dopant and semiconductor are commonly mixed in solution prior to casting the doped film. Recently, sequential doping methods in which the dopant is deposited onto the semiconductor film, either from solution or by evaporation, have increasingly been used. ${ }^{3,4}$ Sequential doping avoids possible complications that arise if the doped material is poorly soluble in the casting solvent and in some cases may allow for the preservation of some of the structural order present in the pristine semiconductor film. Although widely applied to the p-doping of $\mathrm{P}_{3} \mathrm{HT}^{5-8}$ and PBTTT, ${ }^{9,10}$ there are only few reports of the sequential n-doping of solution-processed polymers. ${ }^{11}$

The air-stability of oxidants, hole-transport materials, and their doped combinations often allow for easy handling in air. Highly conductive hole-transport materials are achievable in many polymer-dopant systems. ${ }^{7,12-16}$ In contrast, electrontransport materials and their n-doped derivatives lag behind p-type polymers in terms of both mobility and conductivity. ${ }^{17-19}$

\footnotetext{
${ }^{a}$ School of Chemistry and Biochemistry, Georgia Institute of Technology, Atlanta, GA 30332, USA. E-mail: seth.marder@chemistry.gatech.edu

${ }^{b}$ School of Materials Science and Engineering, Georgia Institute of Technology, Atlanta, GA 30332, USA

${ }^{c}$ George W. Woodruff School of Mechanical Engineering,

Georgia Institute of Technology, Atlanta, GA 30332, USA

$\dagger$ Electronic supplementary information (ESI) available. See DOI: 10.1039/d0ma00406e
}

One reason is that the dopant-induced polaronic charge carriers tend to be localized on acceptor moieties, and the electronic coupling between adjacent acceptor sites is often poor. ${ }^{20-22}$

Conjugated polymers incorporating naphthalene diimides (NDIs) comprise a prominent family of electron-transporting semiconducting polymers and are reduced at moderate potentials of $c a .-1.0 \mathrm{~V} v$ s. ferrocene. ${ }^{22-24}$ Although a great diversity of NDI polymers have been reported, most n-doping studies have focused on the NDI/bithiophene copolymer P(NDIOD-T2) (Fig. 1) and materials closely related to it. ${ }^{23-26}$ Moreover, few of these studies have employed sequential doping. ${ }^{11}$

PNBS is a copolymer of an NDI monomer and a selenopheneflanked benzodithiazole (Fig. 1$)^{27}$ and exhibits a field-effect electron mobility value of $8.5 \mathrm{~cm}^{2} \mathrm{~V}^{-1} \mathrm{~s}^{-1}$, which is larger than values reported for other NDI polymers. ${ }^{28,29}$ This large value raises the possibility of obtaining high conductivity values if high chargecarrier densities can be obtained through doping without adversely affecting this mobility. Here we report on the electrical properties of films obtained through the sequential doping of PNBS with the moderately air-stable n-dopants $\left(\mathrm{RuCp}^{*} \mathrm{mes}\right)_{2},(\mathrm{~N}-\mathrm{DMBI})_{2}$, and N-DMBI-H (Fig. 1). Although the conductivity values are modest, we have been able to investigate carrier transport as a function of doping level in the films through variable-temperature conductivity measurements. We have also examined doping-induced changes in the ordering of the film through GIXRD.

\section{Results and discussion}

Polymer and dopants used

As discussed above, PNBS $^{22}$ (see Experimental section and ESI, $\dagger$ Fig. S1 and S2) was chosen for sequential doping studies owing 


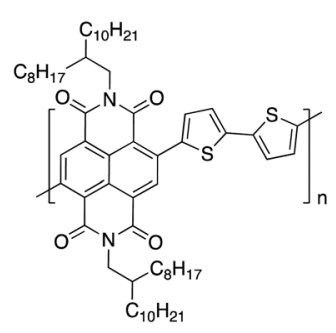

P(NDIOD-T2)

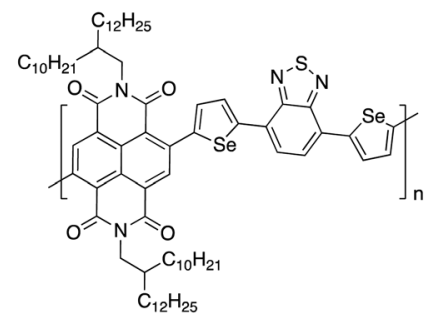

PNBS
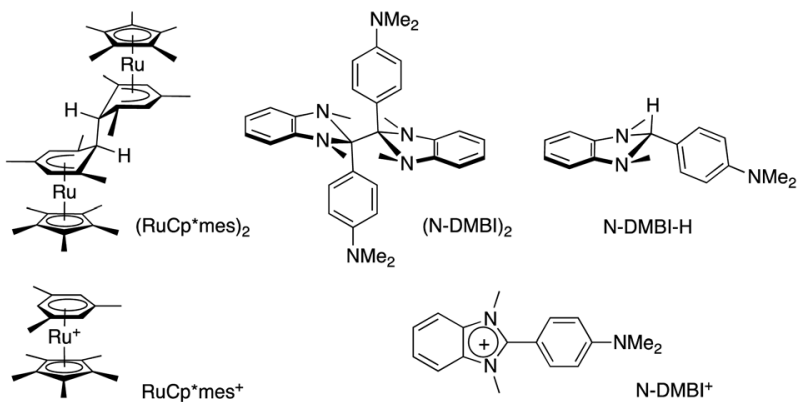

Fig. 1 Chemical structures of the polymers P(NDIOD-T2) and PNBS, the $n$-dopants (RuCp*mes) 2 ( N-DMBI) , and N-DMBI-H, and the corresponding cations formed upon doping.

to the high electron-mobility values reported for the pristine polymer. Of the three dopants investigated, N-DMBI-H is the most stable to ambient conditions, but also expected to be the least reactive dopant towards NDI materials, ${ }^{30}$ while, in some cases of its use, hydrogenated side products have been observed in addition to the desired $\mathrm{N}^{-\mathrm{DMBI}^{+}}$dopant ion and the semiconductor radical anion. ${ }^{31}$ Although it has been widely used as an n-dopant for NDI polymers including P(NDIOD-T2), both its limited reactivity, likely originating from a slow endergonic hydride-transfer step, and poor miscibility with some polymers ${ }^{25}$ have proven obstacles, with thermal annealing often being used to address the former issue..$^{23,24,32}$ The dimer $\left(\mathrm{RuCp}^{*} \mathrm{mes}\right)_{2}$, on the other hand, is strongly reducing and reacts cleanly with the loss of two electrons to form RuCp${ }^{*}$ mes $^{+} ;{ }^{33}$ it has been previously co-deposited with $\mathrm{P}$ (NDIOD-T2) to afford conductivity values up to $10^{-3} \mathrm{~S} \mathrm{~cm}^{-1}$. ${ }^{34}$ We have previously reported that a DMBI dimer is a more effective dopant for P(NDIOD-T2) than its DMBI-H analogue. ${ }^{30}$ We have also recently reported ${ }^{35}$ the dimeric analogue of N-DMBI-H, $(\mathrm{N}-\mathrm{DMBI})_{2}$, and that it leads to higher conductivity values than $\left(\mathrm{RuCp}^{*} \mathrm{mes}\right)_{2}$ in an isoindigo-like polymer, apparently due to the more planar $\mathrm{N}^{-\mathrm{DMBI}^{+}}$ion leading to less disruption of the polymer ordering than the threedimensional $\mathrm{RuCp}^{*} \mathrm{mes}^{+}$ion. $^{35}$ We were thus interested in examining if (N-DMBI$)_{2}$ doping affords any differences in final conductivity values relative to $\left(\mathrm{RuCp}^{*} \mathrm{mes}\right)_{2}$ for the highmobility PNBS, upon sequential doping.

\section{Solution reactivity}

In addition to the sequential doping discussed below, we also investigated the possibility of doping PNBS using concomitant doping in chlorobenzene solution. The utility of this approach was limited by formation of precipitates when (N-DMBI) $)_{2}$ or $\left(\mathrm{RuCp}^{*} \mathrm{Mes}\right)_{2}$ were added to the polymer solution. However, at lower concentrations, where such visible precipitates were not formed ( $\left.c a .10^{-4} \mathrm{M}\right)$, UV-Vis-NIR spectroscopy was used to investigate the reactivity of the dopants with PNBS and to qualitatively asses the extent of doping. Fig. 2a shows the UV-VisNIR spectra of PNBS doped with various proportions of (N-DMBI) $)_{2}$ in chlorobenzene (where $50 \mathrm{~mol} \%$ corresponds to one molecule of dimer per two repeat units, i.e. potentially reduction by one electron per repeat unit). The weakening and broadening of the low-energy feature (Fig. 2a) is similar to what is seen on doping of
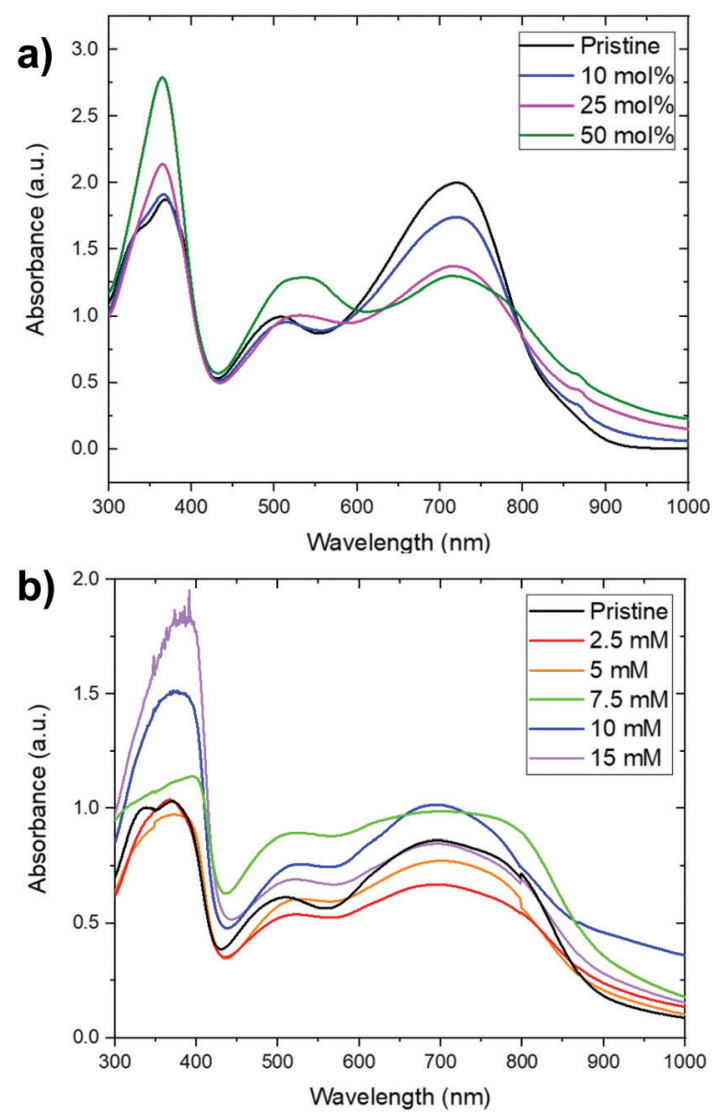

Fig. 2 UV-Vis-NIR spectra for PNBS doped with $(\mathrm{N}-\mathrm{DMBI})_{2}$. (a) Solution doping in chlorobenzene. (b) Sequential doping of films carried out using $n$-butyl acetate solutions of $(\mathrm{N}-\mathrm{DMBI})_{2}$ with the concentrations specified.

other NDI conjugated polymers. ${ }^{26}$ The growth of the feature at

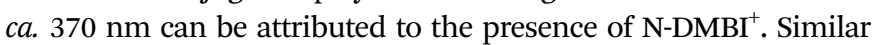
spectral changes, except for the growth of the feature at $c a .370 \mathrm{~nm}$, are seen when doping with $\left(\mathrm{RuCp}^{*} \mathrm{mes}\right)_{2}$, while N-DMBI-H appears not to react under these conditions, consistent with other roomtemperature solution studies of N-DMBI-H with NDI-based polymers,${ }^{36}$ and only to a small extent on brief heating (Fig. S3, ESI $†$ ).

\section{UV-Vis-NIR for sequentially doped films}

We chose $n$-butyl acetate as a solvent for sequential doping since it dissolves the dopants used in this study, but not PNBS. 
Absorption spectra for thin films of PNBS immersed for $1 \mathrm{~min}$ in various concentrations of dopants in $n$-butyl acetate show similar trends to the solution experiments (Fig. $2 \mathrm{~b}$ and Fig. S4, S5, ESI $\dagger$ ), although the initial undoped spectra are broader and the trends are not quite so clear-cut, likely due to variation in film thickness, scattering contributions, and perhaps superposition of features from species doped to different extents from different depths within the film. However, the growth of the feature at $c a .370 \mathrm{~nm}$ indicates incorporation of the dopant counterion, $\mathrm{N}-\mathrm{DMBI}^{+}$, into the films upon sequential doping with $(\mathrm{N}-\mathrm{DMBI})_{2} \cdot{ }^{35}$

\section{Microstructural characterization of doped films}

To achieve high electrical conductivity, in addition to high carrier concentration, a suitable morphology governed by ordering of polymer and microstructure is equally important. To examine PNBS ordering as a function of doping, we performed grazing incidence X-ray diffraction (GIXRD) (Fig. 3). The pristine polymer shows peaks at $2.6 \mathrm{~nm}^{-1}$ and $5.2 \mathrm{~nm}^{-1}$, which, as in previous reports on $\mathrm{PNBS}^{22}$ and on NDI polymers with similar alkyl substituents, ${ }^{37}$ can be assigned to (100) and (200) reflections associated with a lamellar repeat distance of $23 \AA$. The observation of these two reflections indicates that at least a portion of the polymer chains adopt an "edge-on" orientation relative to the surface. As the (N-DMBI) $)_{2}$ concentration used for the sequential doping is increased from 0 to $7.5 \mathrm{mM}$, the (100) peak intensity increases, while greater dopant concentrations
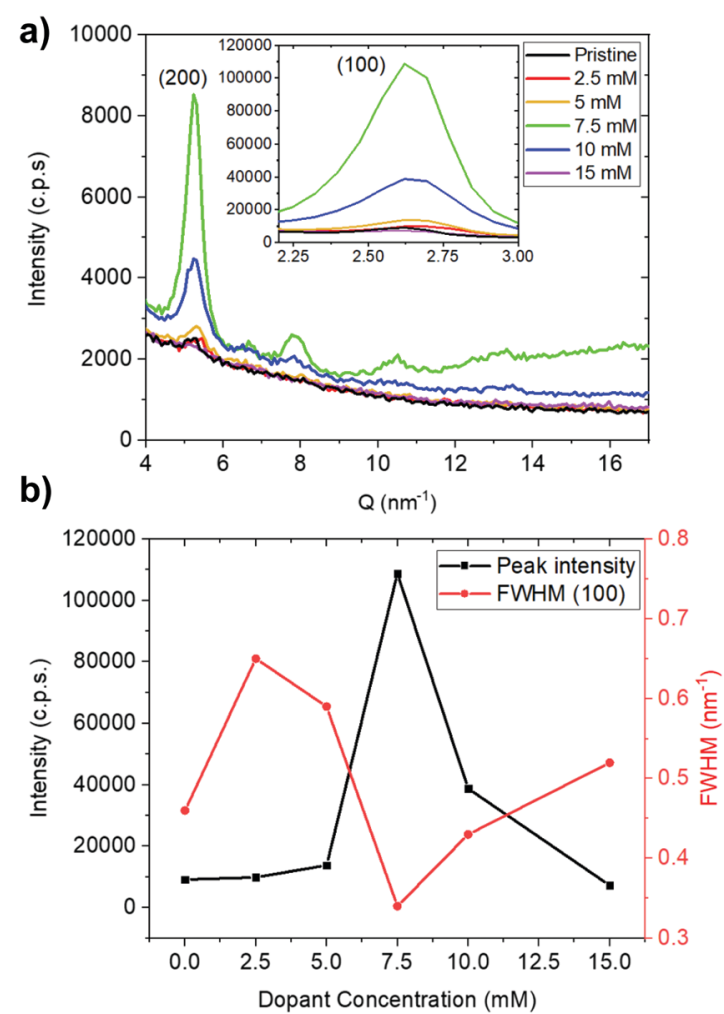

Fig. 3 GIXRD data for pristine and (N-DMBI) ${ }_{2}$-doped PNBS films: (a) diffraction patterns and (b) plots of intensity and full width at half maximum height for the (100) diffraction peaks. leads to a decrease in the (100) intensity. The full width at half maximum (FWHM) for the (100) peak also broadens upon initial doping $(2.5 \mathrm{mM})$, then decreases to a minimum at $7.5 \mathrm{mM}$, then increasing again beyond that. The (100) intensities and FWHM data suggest that the coherence length is maximized and/or lattice disorder is minimized for films doped with $7.5 \mathrm{mM}$ solutions. It is unclear where the dopant ions are located, but the roughly constant $d$-spacing for the (100) reflections suggest that the majority must be located in the $\pi$-stacks, in domains with the different crystalline orientation to those evident in the GIXRD, or in amorphous regions of the polymer. In contrast, when using concentrations of $\left(\mathrm{RuCp}^{*} \mathrm{Mes}\right)_{2}$ in excess of $1 \mathrm{mM}$, the (200) peak is not observable and even the (100) peak is barely discernable (Fig. S6, $\mathrm{ESI} \dagger$ ), presumably indicating that the packing of the crystalline domains of the polymer is significantly disrupted by the bulky 3D RuCp* ${ }^{*}$ es $^{+}$cation. ${ }^{35}$

AFM was used to further examine changes in surface morphology and roughness of doped PNBS films. Fig. S7 (ESI $\dagger$ ) shows AFM micrographs of pristine and (N-DMBI $)_{2}$-doped PNBS films indicating an increase in surface roughness upon doping.

\section{In-plane DC electrical conductivity and temperature dependence}

The electrical conductivity of doped films was evaluated using a custom built 4-point probe in a Van der Pauw configuration. ${ }^{38}$ PNBS films sequentially doped with either N-DMBI-H or $\left(\text { RuCp }{ }^{*} \text { mes }\right)_{2}$ exhibited electrical conductivities below the limit of detection using our equipment $\left(<10^{-5} \mathrm{~S} \mathrm{~cm}^{-1}\right)$. Poor electrical conductivity of PNBS after attempted doping with $\mathrm{N}-\mathrm{DMBI}-\mathrm{H}$ is consistent with the optical data and with some previous reports on concomitant doping that indicate thermal treatments are needed to initiate doping reactions. ${ }^{25,32}$ In previous reports, $\left(\mathrm{RuCp}^{*} \mathrm{mes}\right)_{2}$ was found to be suitable for concomitant doping of $\mathrm{P}(\mathrm{NDIOD}-\mathrm{T} 2),{ }^{34}$ but unsuitable for sequentially doping the same polymer, this unsuitability being attributed to the inability of the dopant to enter the ordered (face-on) film. ${ }^{11}$ In the present case, the reaction clearly occurs, as shown by optical and GIXRD data; presumably the low conductivity results from the disruption of the film packing. However, we observed that PNBS thin films doped with (N-DMBI) ${ }_{2}$ sequentially in air exhibit conductivities approaching $2 \mathrm{mS} \mathrm{cm}{ }^{-1}$ for doping concentrations of $7.5 \mathrm{mM}$ (Fig. 4a). We note, however, that the conductivity values for films treated with all three dopants may be compromised by the slight sensitivities of the doped material to air (see below and Fig. 4b).

The dopant levels that give the highest conductivity values coincide with those that give the strongest and narrowest (100) reflections in GIXRD measurements (Fig. 3 and Fig. S5, ESI $\dagger$ ). However, despite the high charge-carrier mobility reported for pristine PNBS and the apparent enhancement of ordering on optimal doping, the maximum conductivity values are comparable to other values reported for many NDI polymers, although falling short of those reported for some examples, especially those with oligoether side chains. ${ }^{22,27,31,39,40}$ Fig. $4 \mathrm{~b}$ shows the 
a)

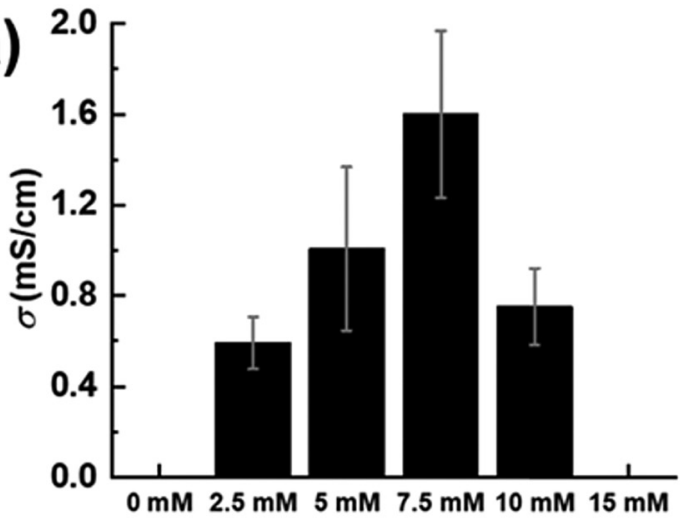

b)

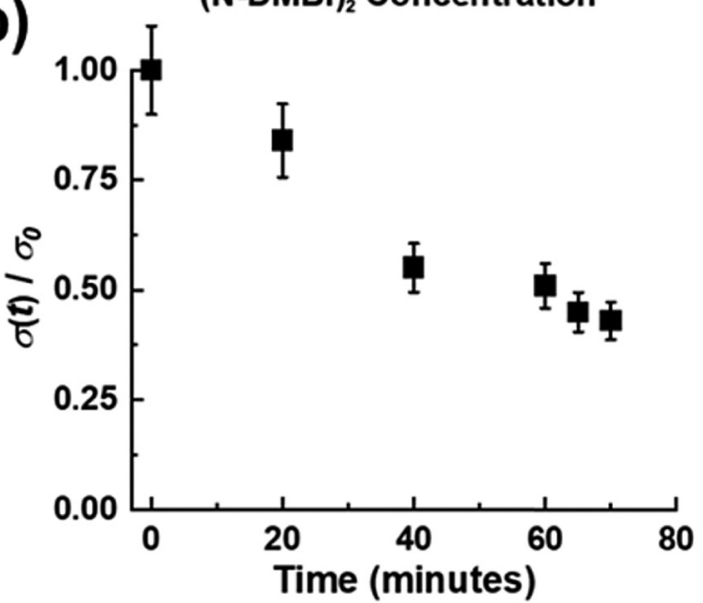

Fig. 4 Electrical conductivity as a function of doping and time. (a) PNBS electrical conductivity as a function of $(\mathrm{N}-\mathrm{DMBI})_{2}$ dopant concentration. Error bars represent sample to sample variation (3 samples). (b) Electrical conductivity of $7.5 \mathrm{mM}$ doped PNBS films as a function of time. Error bars represent imprecision in the measurement of the resistance value at time $(t)$.

electrical conductivity of the optimally (N-DMBI) ${ }_{2}$-doped film as a function of exposure to air and indicates a decrease of ca. $20 \%$ over 20 minutes exposure, indicating that the exposure necessary for our measurement system does not have a large impact on the conductivity values, although, as noted above, some degradation could have already occurred during the doping process.

To further characterize charge transport, temperaturedependent electrical conductivities were measured. ${ }^{38,41}$ As expected, the conductivity was found to increase exponentially with temperature (Fig. 5a), consistent with the expectation for thermally-activated hopping of carriers. ${ }^{36,37}$ The data could accordingly be fit to obtain the theoretical maximum (infinite temperature) electrical conductivity $\left(\sigma_{0}\right)$ and the activation energy $\left(E_{\mathrm{a}}\right)$ using the Mott Polaron Model (eqn (1) and (2))

$$
\begin{gathered}
\sigma=\sigma_{0} \exp \left(\frac{-E_{\mathrm{a}}}{k_{\mathrm{b}} T}\right) \\
\ln (\sigma)=\ln \left(\sigma_{0}\right)+\left(\frac{-E_{\mathrm{a}}}{k_{\mathrm{b}} T}\right)
\end{gathered}
$$

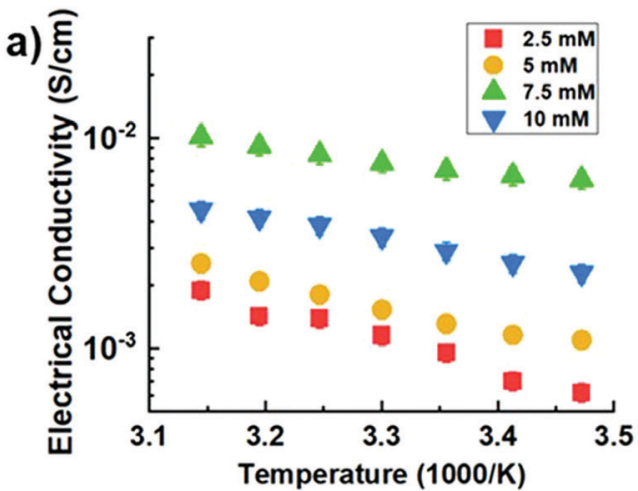

b)

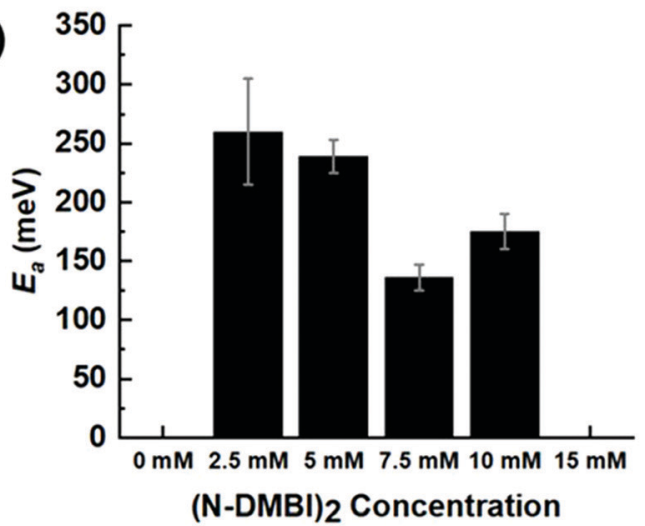

c)

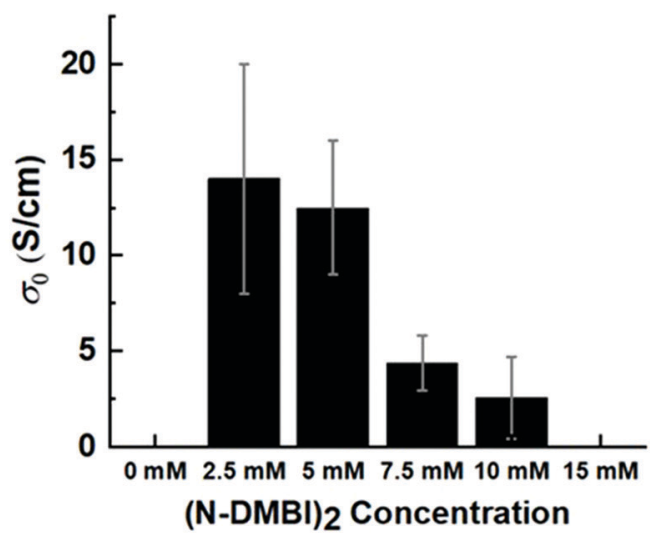

Fig. 5 Temperature dependent PNBS electrical conductivity measurements. (a) Representative electrical conductivities as a function of doping and temperature. Error bars represent measurement error. (b) Activation energies and $(c)$ intrinsic conductivities as calculated by the Mott Polaron Model. Error bars represent sample to sample errors.

and analyzed statistically using $t$-tests with $95 \%$ confidence intervals. ${ }^{21,33,38}$

Fig. 5c shows $\sigma_{0}$ for each dopant system, whereby $\sigma_{0}$ is the pre-exponential conductivity that heavily depends on film morphology and hopping distance and represents a maximum electrical conductivity achievable. We find that $\sigma_{0}$ is $c a .12 \mathrm{~S} \mathrm{~cm}^{-1}$ for lightly doped PNBS (2.5 and $5 \mathrm{mM}$ dopant solutions) but decreases to $c a .2 .5 \mathrm{~S} \mathrm{~cm}^{-1}$ for more heavily doped PNBS (7.5, $10 \mathrm{mM}$ dopant solutions). Lastly, it has been reported in many studies that $\sigma_{0}$ increases with increased doping to a maximum and then decreases again. ${ }^{38}$ 
Fig. 5b shows the effective barrier for charge transport, $E_{\mathrm{a}}$, for each dopant concentration; it is effectively the same at low doping levels $(2.5,5 \mathrm{mM})$ but is significantly lower at $7.5 \mathrm{mM}$ (highest conductivity). This is consistent with what is generally seen for trends in $E_{\mathrm{a}}$ with increasing dopant concentration. In this case, as the dopant concentration is further increased, $E_{\mathrm{a}}$ increases again. ${ }^{38}$ Thus, the lowest $E_{\mathrm{a}}$ values correspond to the films that GIXRD suggests to be the most ordered. The barriers are similar in size to those reported for other n-doped NDI polymers. ${ }^{22,27,31,39,40}$

\section{Conclusion}

The high electron-mobility polymer (PNBS) has been sequentially doped with several dopants and doping concentration. The recently reported dimer $(\mathrm{N}-\mathrm{DMBI})_{2}$ is more effective dopant for the sequential doping approach of PNBS than either $\left(\text { RuCp}^{*} \text { mes }\right)_{2}$ and N-DMBI-H, because of its ability to both successfully dope PNBS and improve structural ordering. $(\mathrm{N}-\mathrm{DMBI})_{2}$ doping results in a maximum electrical conductivity of $c a .2 \mathrm{mS} \mathrm{cm}^{-1}$; the doping can be reproducibly carried out in air. The temperature dependent electrical properties further our understanding of structural and energetic contributions to electrical transport.

\section{Materials and methods}

PNBS $\left(M_{\mathrm{n}}=42 \mathrm{kDa}\right),(\mathrm{N}-\mathrm{DMBI})_{2}, \mathrm{~N}-\mathrm{DMBI}-\mathrm{H}$, and $\left(\mathrm{RuCp}{ }^{*} \mathrm{mes}\right)_{2}$ were synthesized according to modified literature procedures. ${ }^{27,31,35}$ Other solvents and materials including $n$-butyl acetate, were purchased from Sigma Aldrich and used as received.

Microscope glass slides were sonicated in deionized water, followed by acetone then isopropanol and then dried using nitrogen gas, followed by oxygen plasma treatment for $10 \mathrm{~min}$. The PNBS polymer solution $\left(8 \mathrm{mg} \mathrm{mL}^{-1}\right.$ in 1,2-dichlorobenzene) was then drop cast on top of the glass slides in air. The films were doped by a (N-DMBI) $)_{2}$ solution (of the desired concentration, also in air) in $n$-butyl acetate, then spun at $800 \mathrm{rpm}$ for $30 \mathrm{~s}$ to remove excess solvent, again in air. Soaking the substrate for longer periods of time $(1 \mathrm{~min}, 2 \mathrm{~min}$ and $5 \mathrm{~min}$ ) did not show an impact on conductivity. The same procedure was used for N-DMBI-H and (RuCp*Mes) $)_{2}$.

UV-vis-NIR absorption data were acquired on a Cary 5000 instrument for both the solid and solution spectra. GIXRD data were acquired on Panalytical Emperyan XRD instrument with a $1.54 \AA \mathrm{Cu} \mathrm{K} \alpha(\lambda=1.5406 \AA)$ source, and by setting the $\omega$ offset to $\omega=0.003^{\circ}$ in order to fix the penetration depth across measured samples.

Atomic force microscopy (AFM) height images were collected on a Bruker Dimension Icon, with RTESP-150 probes operating in standard tapping mode just below $150 \mathrm{kHz}$. The scanning rate was fixed to $0.25 \mathrm{~Hz}$ across the samples.

DC electrical conductivity and temperature dependent electrical conductivity measurements were performed on a custom-built setup thoroughly described elsewhere. ${ }^{38}$ Briefly, thin films were cut into $c a .1 \mathrm{~cm}^{2}$ samples and four Platinum contact pads were deposited in a van der Pauw geometry using a custombuilt sputtering chamber and shadow mask. Films were then doped with $250 \mu \mathrm{L}$ of the appropriate dopant solution and permitted to soak for $1 \mathrm{~min}$ before excess solvent and dopant were removed via spinning at ca. $800 \mathrm{rpm}$ for $30 \mathrm{~s}$. One film was doped at a time and then immediately measured to mitigate any effects on measured electrical properties of de-doping through reaction with atmospheric oxygen or water.

\section{Conflicts of interest}

There are no conflicts of interest to declare.

\section{Acknowledgements}

This work was supported by the National Science Foundation (through DMR-1807797 and through the DMREF program DMR-1729737). This work was performed in part at the Georgia Tech Institute for Electronics and Nanotechnology, a member of the National Nanotechnology Coordinated Infrastructure (NNCI), which is supported by the National Science Foundation (Grant ECCS-1542174). S. A. G. thanks the Office of Naval Research (award number N00014-19-1-2162), Department of Education Graduate Assistance in Areas of National Need (GAANN) program at the Georgia Institute of Technology (Award \#P200A180075), Link Energy Foundation, and the Science and Technology of Material Interfaces (STAMI) group at the Georgia Institute of Technology. S. J. thanks the United States-India Educational Foundation (USIEF, India) and Institute of International Education (IIE, USA) for a FulbrightNehru Postdoctoral Fellowship (Grant No. 2266/FNPDR/2017)

\section{References}

1 S. Barlow, S. R. Marder, A. Khan, X. L. Lin and F. Zhang, in Conjugated Polymers, ed. J. Reynolds, B. C. Thompson and T. A. Skotheim, CRC press, Boca Raton, 4th edn, 2019, ch. 2.

2 K. Walzer, B. Maennig, M. Pfeiffer and K. Leo, Chem. Rev., 2007, 107, 1233-1271.

3 T. J. Aubry, K. J. Winchell, C. Z. Salamat, V. M. Basile, J. R. Lindemuth, J. M. Stauber, J. C. Axtell, R. M. Kubena, M. D. Phan, M. J. Bird, A. M. Spokoyny, S. H. Tolbert and B. J. Schwartz, Adv. Funct. Mater., 2020, 2001800.

4 K. Kang, S. Watanabe, K. Broch, A. Sepe, A. Brown, I. Nasrallah, M. Nikolka, Z. Fei, M. Heeney, D. Matsumoto, K. Marumoto, H. Tanaka, S.-I. Kuroda and H. Sirringhaus, Nat. Mater., 2016, 15, 896-902.

5 M. T. Fontana, D. A. Stanfield, D. T. Scholes, K. J. Winchell, S. H. Tolbert and B. J. Schwartz, J. Phys. Chem. C, 2019, 123, 22711-22724.

6 E. Lim, K. A. Peterson, G. M. Su and M. L. Chabinyc, Chem. Mater., 2018, 30, 998-1010. 
7 V. Vijayakumar, Y. Zhong, V. Untilova, M. Bahri, L. Herrmann, L. Biniek, N. Leclerc and M. Brinkmann, Adv. Energy Mater., 2019, 9, 1900266.

8 C. T. Hong, Y. Yoo, Y. H. Kang, J. Ryu, S. Y. Cho and K.-S. Jang, RSC Adv., 2015, 5, 11385-11391.

9 S. Patel, A. Glaudell, K. Peterson, E. Thomas, K. O’Hara, E. Lim and M. Chabinyc, Sci. Adv., 2017, 3, E1700434.

10 T. Ma, B. X. Dong, G. L. Grocke, J. Strzalka and S. N. Patel, Macromolecules, 2020, 53, 2882-2892.

11 E. E. Perry, C.-Y. Chiu, K. Moudgil, R. A. Schlitz, C. J. Takacs, K. A. O'Hara, J. G. Labram, A. M. Glaudell, J. B. Sherman, S. Barlow, C. J. Hawker, S. R. Marder and M. L. Chabinyc, Chem. Mater., 2017, 29, 9742-9750.

12 R. Kroon, D. A. Mengistie, D. Kiefer, J. Hynynen, J. D. Ryan, L. Yu and C. Muller, Chem. Soc. Rev., 2016, 45, 6147-6164.

13 O. Bubnova and X. Crispin, Energy Environ. Sci., 2012, 5, 9345-9362.

14 S. L. Pittelli, S. A. Gregory, J. F. Ponder, S. K. Yee and J. R. Reynolds, J. Mater. Chem. C, 2020, 8, 7463-7475.

15 F. Zhong, X. Yin, Z. Chen, C. Gao and L. Wang, ACS Appl. Mater. Interfaces, 2020, 12, 26276-26285.

16 T. P. Kaloni, P. K. Giesbrecht, G. Schreckenbach and M. S. Freund, Chem. Mater., 2017, 29, 10248-10283.

17 S. Fabiano, S. Braun, X. Liu, E. Weverberghs, P. Gerbaux, M. Fahlman, M. Berggren and X. Crispin, Adv. Mater., 2014, 26, 6000-6006.

18 Z. Bin, Z. Liu, Y. Qiu and L. Duan, Adv. Opt. Mater., 2018, 6, 1800536.

19 Y. Lu, J.-Y. Wang and J. Pei, Chem. Mater., 2019, 31, 6412-6423.

20 C.-Y. Yang, W.-L. Jin, J. Wang, Y.-F. Ding, S. Nong, K. Shi, Y. Lu, Y.-Z. Dai, F.-D. Zhuang, T. Lei, C.-A. Di, D. Zhu, J.-Y. Wang and J. Pei, Adv. Mater., 2018, 30, 1802850.

21 B. D. Naab, X. Gu, T. Kurosawa, J. W. F. To, A. Salleo and Z. Bao, Adv. Electron. Mater., 2016, 2, 1600004.

22 J. Liu, Y. Shi, J. Dong, M. I. Nugraha, X. Qiu, M. Su, R. C. Chiechi, D. Baran, G. Portale, X. Guo and L. J. A. Koster, ACS Energy Lett., 2019, 4, 1556-1564.

23 R. Matsidik, H. Komber, A. Luzio, M. Caironi and M. Sommer, J. Am. Chem. Soc., 2015, 137, 6705-6711.

24 R. Matsidik, A. Luzio, S. Hameury, H. Komber, C. R. McNeill, M. Caironi and M. Sommer, J. Mater. Chem. C, 2016, 4, 10371-10380.

25 R. A. Schlitz, F. G. Brunetti, A. M. Glaudell, P. L. Miller, M. A. Brady, C. J. Takacs, C. J. Hawker and M. L. Chabinyc, Adv. Mater., 2014, 26, 2825-2830.

26 J. Liu, L. Qiu, R. Alessandri, X. Qiu, G. Portale, J. Dong, W. Talsma, G. Ye, A. A. Sengrian, P. C. T. Souza, M. A. Loi,
R. C. Chiechi, S. J. Marrink, J. C. Hummelen and L. J. A. Koster, Adv. Mater., 2018, 30, 1704630.

27 Z. Zhao, Z. Yin, H. Chen, L. Zheng, C. Zhu, L. Zhang, S. Tan, H. Wang, Y. Guo, Q. Tang and Y. Liu, Adv. Mater., 2017, 29, 1602410.

28 Z. Yuan, C. Buckley, S. Thomas, G. Zhang, I. Bargigia, G. Wang, B. Fu, C. Silva, J.-L. Brédas and E. Reichmanis, Macromolecules, 2018, 51, 7320-7328.

29 M. J. Sung, A. Luzio, W.-T. Park, R. Kim, E. Gann, F. Maddalena, G. Pace, Y. Xu, D. Natali, C. de Falco, L. Dang, C. R. McNeill, M. Caironi, Y.-Y. Noh and Y.-H. Kim, Adv. Funct. Mater., 2016, 26, 4984-4997.

30 B. D. Naab, S. Zhang, K. Vandewal, A. Salleo, S. Barlow, S. R. Marder and Z. Bao, Adv. Mater., 2014, 26, 4268-4272. 31 B. D. Naab, S. Guo, S. Olthof, E. G. B. Evans, P. Wei, G. L. Millhauser, A. Kahn, S. Barlow, S. R. Marder and Z. Bao, J. Am. Chem. Soc., 2013, 135, 15018-15025.

32 B. Saglio, M. Mura, M. Massetti, F. Scuratti, D. Beretta, X. Jiao, C. R. McNeill, M. Sommer, A. Famulari, G. Lanzani, M. Caironi and C. Bertarelli, J. Mater. Chem. A, 2018, 6, 15294-15302.

33 S. Guo, S. B. Kim, S. K. Mohapatra, Y. Qi, T. Sajoto, A. Kahn, S. R. Marder and S. Barlow, Adv. Mater., 2012, 24, 699-703. 34 Y. Zhang, H. Phan, H. Zhou, X. Zhang, J. Zhou, K. Moudgil, S. Barlow, S. R. Marder, A. Facchetti and T.-Q. Nguyen, Adv. Electron. Mater., 2017, 3, 1600546.

35 H.-I. Un, S. A. Gregory, S. K. Mohapatra, M. Xiong, E. Longhi, Y. Lu, S. Rigin, S. Jhulki, C.-Y. Yang, T. V. Timofeeva, J.-Y. Wang, S. K. Yee, S. Barlow, S. R. Marder and J. Pei, Adv. Energy Mater., 2019, 9, 1900817.

36 D. Kiefer, A. Giovannitti, H. Sun, T. Biskup, A. Hofmann, M. Koopmans, C. Cendra, S. Weber, L. J. Anton Koster, E. Olsson, J. Rivnay, S. Fabiano, I. McCulloch and C. Muller, ACS Energy Lett., 2018, 3, 278-285.

37 J. Rivnay, M. F. Toney, Y. Zheng, I. V. Kauvar, Z. Chen, V. Wagner, A. Facchetti and A. Salleo, Adv. Mater., 2010, 22, 4359-4363.

38 S. A. Gregory, A. K. Menon, S. Ye, D. S. Seferos, J. R. Reynolds and S. K. Yee, Adv. Energy Mater., 2018, 8, 1802419.

39 S. Riera-Galindo, A. Orbelli Biroli, A. Forni, Y. Puttisong, F. Tessore, M. Pizzotti, E. Pavlopoulou, E. Solano, S. Wang, G. Wang, T. P. Ruoko, W. M. Chen, M. Kemerink, M. Berggren, G. di Carlo and S. Fabiano, ACS Appl. Mater. Interfaces, 2019, 11, 37981-37990.

40 S. Guo, S. K. Mohapatra, A. Romanov, T. V. Timofeeva, K. I. Hardcastle, K. Yesudas, C. Risko, J.-L. Brédas, S. R. Marder and S. Barlow, Chem. - Eur. J., 2012, 18, 14760-14772.

41 N. F. Mott and E. A. Davis, Electronic Processes in NonCrystalline Materials, Oxford University Press, 2nd edn, 1979. 